\title{
Experimental Study of Humidification AndDehumidification Desalination Process
}

\author{
Faissal Abdel-Hady ${ }^{\# 1}$, Mahmoud M. El-Halwagi ${ }^{* 2}$, Mohammed Alghamdi ${ }^{\# 3}$, A.K. Mazher ${ }^{\$ 4}$, \\ Abdulrahim Alzahrani ${ }^{\# 5}$ \\ \# Chemical and Materials Engineering Department, King Abdulaziz University, Jeddah, KSA \\ *Department of Chemical Engineering, Texas A\&M University, College Station, TX 77843, USA \\ ${ }^{\$}$ Nuclear Engineering Department, King Abdul-Aziz University, Jeddah, KSA \\ ${ }^{1}$ faissalhady@gmail.com, ${ }^{2}$ mahmoud.elhalwagi@gmail.com \\ ${ }^{3}$ mohammed_moghram@hotmail.com, , ${ }^{4}$ ben.muzhar@gmail.com, ${ }^{5}$ azahrani@kau.edu.sa
}

\begin{abstract}
The humidification-dehumidification process (HDH) is a thermal technique adapted for water desalination. This technique has many advantages such as moderate installation, simplicity and operates at relatively low temperatures when compared with other commercial thermal processes. HDH process is perfectly suitable for the decentralized areas where a small-scale desalination technology uses renewable resources of energy. The aim of this paper is to present the experimental analysis of the process providing the principle of functioning and the characteristics of the process when a different key variable such as air flow rate and humidifier inlet water temperature is altered. The experiment designed, installed and operated where air flow rates tested at constant humidifier inlet water temperature. To study the influence of air flow rate variation on the system, several experimental runs are implemented at different air flow rates at constant inlet water temperature. The experiments are repeated where humidifier inlet water temperature is changed. The system evaluated after steady state operation within one hour, and the production is collected. Finally, the system analyzed to find the effect of air/water flow ratio on the system productivity, humidifier mass transfer coefficient and dehumidifier overall heat transfer coefficient. Moreover, the sensible heat from the humidifier inlet water is studied as the analysis includes the inlet water temperature effect on the process. The system best results obtained at the maximum tested air flow rate where the GOR was 0.22 and the production cost of $0.043 \mathrm{US} \$ /$ liter.The highest productivity of the system found to be $5.424 \mathrm{l} / \mathrm{hr}$ at $50{ }^{\circ} \mathrm{C}$ humidifier inlet water temperature. The general outcome of the study provides that HDH desalination process is more favorable towards increasing the air flow rates and humidifier inlet water temperature where the mass transfer and overall heat transfer coefficients also increased. The system optimized for best economic and operating conditions.
\end{abstract}

Keyword - Desalination, Humidification, Dehumidification, Design.

\section{INTRODUCTION}

Large parts of Saudi Arabia are water-stressed. Large-scale desalination technologies have become widely available as commercial technology over the last few decades. On the other hand, small-scale desalination technologies for arid areas have not attracted similar commercial interests. The major challenges for a remote water production are the need for systems that incur simplicity, inexpensive components, the ability to adapt to renewables, and ensure relatively maintenance-free operation. Also it is recommended to study simplest efficient designs in order to be used for arid areas. El-Halwagi [1] provided the shortcut method for the design of once-through multi-stage flash (MSF) in order to obtain better design analysis of the unit components and process integration which reveals favorable results compared with the existing plant data. Desalination processes such as Multi-effect distillation (MED), reverse osmosis (RO) are optimized for better operation, design and best economic output [2]-[4] to satisfy the fresh water demand.Among the many available technologies, humidification-dehumidification (HDH) desalination technology is the promising and decentralized drinking water technology. The process includes simple and separate components for each of the thermal processes; this allows each component to be independently designed, which require less capital cost. It can operate over a wide range of raw water quality without the need for complex maintenance and operations. One of the features of the HDH concept is the ability to operate at low temperature that makes it one of the best solar energy applications. In order to improve the water productivity of HDH experimental analysis of the process is needed. The process also known to be sensitive to many variable which affect the productivity such as air flow, feed water flow, feed water temperature, and the configuration of the major components. The productivity of the system has shown a certain improvement with increasing the water temperature and air flow [5], although this increase has optimum value for each parameter [6]. When the energy performance of the process concerned, the mass of water produced per unit heat can be analyzed by obtaining the gained output ratio (GOR) [7]-[9]. Both unit productivity and GOR are affected positively by increasing the feed water temperature [10]. The investigation of pulsed water flow and its effect on the performance of the (HDH) process 
have been analyzed by El-Shazly et al. [8]. It has been found that the unit productivity increased by increasing the off time of the consequent pulses comparing to the continuous flow. Humidification process can be performed either by spray humidifier or pad humidifier, and the study of both systems revealed that the pad humidifier is more appropriate for air humidification [11]. Cemil et al. [12] tested the HDH using humidifier provided with water storage tank. The productivity increased by increasing of feed water flow rate and the water inside the storage tank and showed no significantimprovement when air flow increased. Cooling water flow and its temperature can increase the system productivity [12]. In HDH process the ambient conditions affect the unit performance especially when coupled with a solar energy source, hence it affects the unit productivity [13]. The exergy efficiency is higher in the shorter humidifier tower with a large diameter, which is an important factor in the design of HDH desalination process [14]. The relative humidity is the key factor in HDH desalination; it can reveal more production of the system if increased as possible. Humidifiers can provide the high relative humidity, which ranges between $80 \%$ to $90 \%$ [15]. The relative humidity is considered the driving force of the process, which can be improved by good design of the humidifier. The configuration of the system has a greater impact on the productivity. Appling the forced circulation throughout the humidifier can increase the system productivity [16] especially in the case of a gummy bag cloth. It was also reported that both heat and mass transfer coefficients of the HDH desalination could be improved by increasing of water temperature and air flow rate [17].Since the HDH desalination process has different components to integrate the process, hence the key performance indicators "KPI" could be used to improve the process outcomes. El-Halwagi [18] described the importance of process economic integration with sustainability. The economic evaluation of the HDH process can be extended to cover the impacts on the process sustainability. In the design stage of HDH desalination system, benchmarking and economic analysis can be used for evaluating the sustainability metrics of the process relative to the capital cost. Applying economic evaluation and the sustainability metrics for the designed unit would be a powerful tool for project decision making. Also, it is contributing the process improvement in terms of different arrangments beyond the only economic profitability analysis.Research on HDH desalination technology was undertaken at King Abdul Aziz University in Jeddah city. The unit is constructed by fabricating each component of the system locally. The aim of this work is to analyze the system performance standalone and provide the results of mass transfer coefficients at different air flow rates. This analysis can provide the expected desalination process outcome in the specified area and layout the data for future work when coupled with a renewable energy source.

\begin{tabular}{llll} 
& \multicolumn{2}{c}{ Nomenclature } & \\
$H$ & Enthalpy & $V$ & Volume of the humidifier \\
$T_{a}$ & Air temperature & $Q_{i n}$ & Heat transfer rate \\
$T_{w}$ & Water temperature & $P$ & Capital cost \\
$T_{w}$ & Cooling water temperature & $i$ & Interest rate \\
$T_{M U}$ & Make water temperature & $n$ & Number of years \\
$T o i l$ & Oil temperature & $C_{A}$ & Annual capital cost \\
$m_{a}$ & Air flow rate & $C_{M}$ & Maintenance cost \\
$m_{w}$ & Water flow rate & $C_{O P}$ & Operating cost \\
$m_{c w}$ & Cooling water flow rate & $C_{T O P}$ & Total operating cost \\
$m_{d}$ & Product water flow rate & $P_{T}$ & Total pressure \\
$m_{M U}$ & Make up water flow rate & Greek symbols \\
$M_{o i l}$ & Oil flow rate & $\omega$ & Absolute humidity \\
$\mathrm{Z}$ & Fill height & $\eta_{H}$ & Humidifier efficiency \% \\
$S$ & Cross section of humidifier & Subscripts \\
$c_{a}$ & Specific heat of humid air & $a s$ & Saturated air \\
$c_{w}$ & Specific heat of water & $a v g$ & Average value \\
$h_{f g}$ & Latent heat of evaporation of water & $m$ & Mean value \\
$a$ & Interface area & $i$ & Interface \\
$A$ & Surface area & DH & Dehumidifier \\
$U$ & Overall heat transfer coefficient of dehumidifier & $l m$ & Log mean \\
$P_{v}$ & Vapor pressures & $a$ & Air \\
$K_{y}$ & Gas phase mass transfer coefficient of humidifier & $s$ & Saturated
\end{tabular}




\section{EXPERIMENTAL SETUP AND PROCEDURE}

\section{A. Experimental setup}

The objective of this work is to design, build and test the humidification-dehumidification desalination system. Figure-1 illustrates a schematic diagram of the experimental setup. Humidification occurs in the humidifier while dehumidification occurs in the condenser.

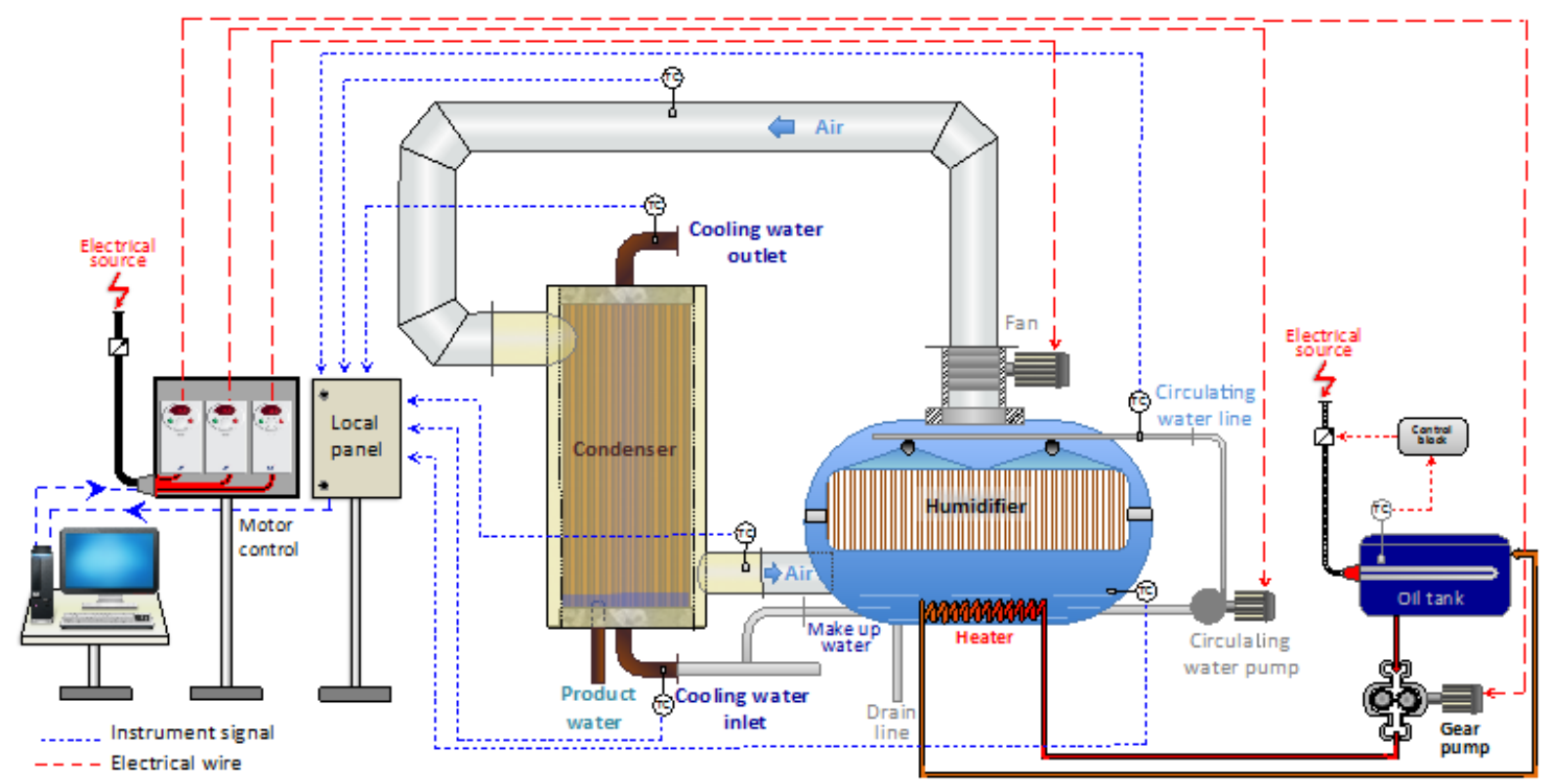

Fig. 1. Schematic diagram of the experimental setup.

The humidifier used is spray chamber type where the liquid is sprayed as a mist and the chamber packed with canvas. The fan is located at the top of the humidifier where the air is pulled from the bottom side opening of air return line from the dehumidifier. The air is flowing countercurrent to the circulating water direction. The circulating water through the humidifier is heated by oil/water heat exchanger. The electrical heater maintains the temperature of the oil. While air is forced to flow trough a packed humidifier, hence air is humidified. At the wet packing surface, the mass and heat transferred to the flowing air. Makeup line provided in order to compensate the water being removed from the humidifier by the air. The experiment setup at the site is shown in figure-2.

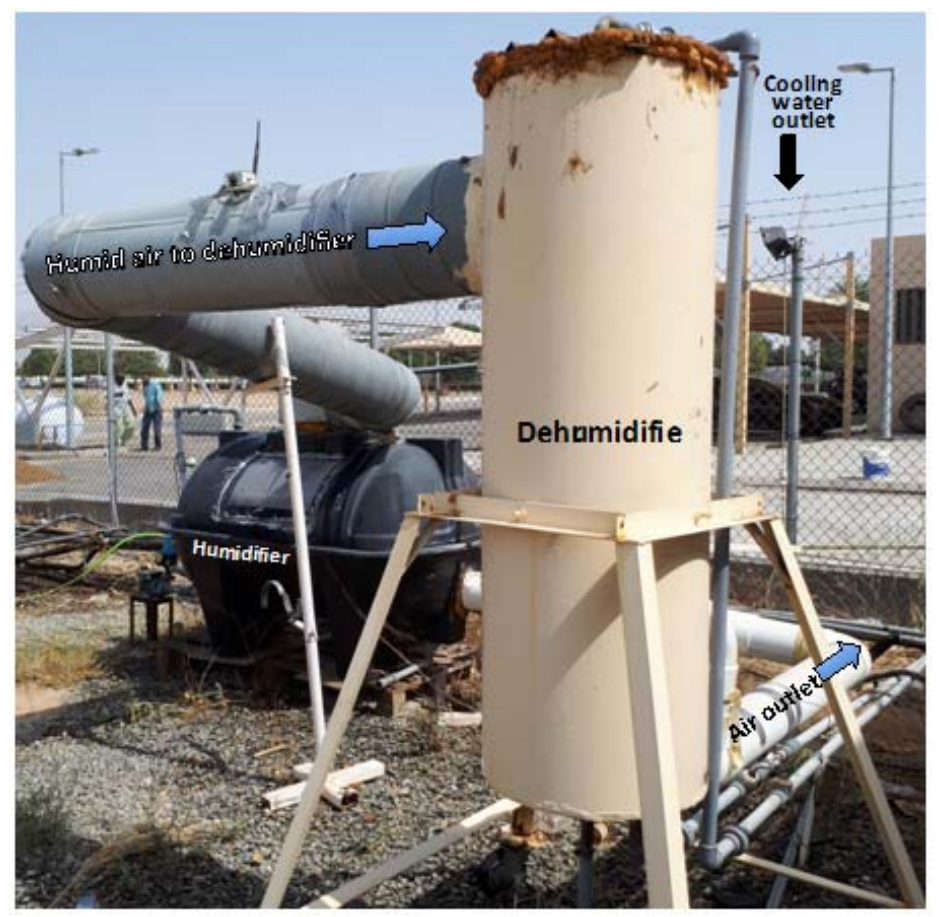

Fig. 2. The experimental setup at the site. 
The air is dehumidified in the condenser where the hot air/water vapor mixture contacted the cold surface. In the condenser, water vapor condenses and air temperature cooled down. Moreover, the sensible heat and latent heat are transferred to the cooling water. The condenser is one pass and designed to have countercurrent flow between the air/water vapor and the cooling water. The cooling water supplied from the reservoir by pump allowing it to enter from the bottom and returns from the top. The air/water vapor mixture enters from the top of the condenser to the bottom. The water level inside the humidifier is maintained by level float valve and adjusted to be below the air return line from the condenser. Moreover, the water in the humidifier can be drained if necessaryby the drain line. The condensed water from air/water vapor mixture is drowned out from the bottom of the condenser and collected.

1) Humidifier: The humidifier designed to have both spray water nozzles and internal packing to increase the surface area between the air and water. The packing and humidifier dimensions are illustrated in figure-3. The spray system consists of two nozzles mounted at the top of the humidifier to spray the water downwards with $0.57 \mathrm{l} / \mathrm{hr}$ circulating water.

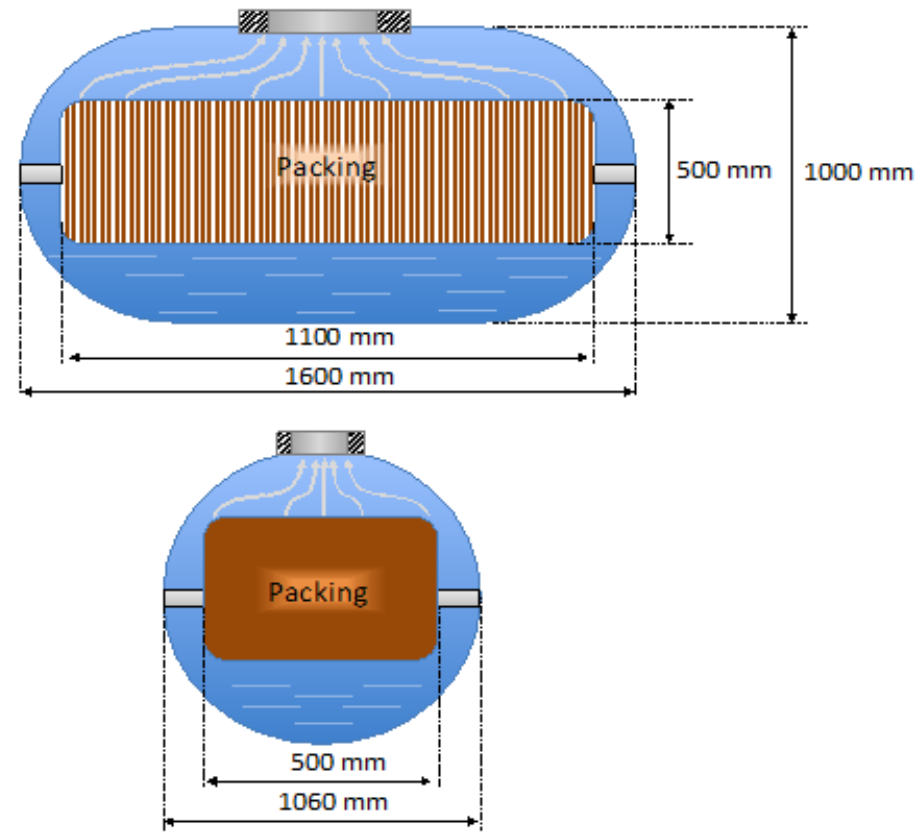

Fig. 3. Schematic diagram of the humidifier.

The nozzles ensured to cover all the packing area for proper distribution of the water across the required air/water contact area. It was aimed to use a simple available material for building the humidifier; hence the canvas packing is used. The width of the humidifier is greater than the height; this is selected to have better humidifying performance rather than using taller humidifier [14].

2) Dehumidifier: The water-cooled heat exchanger is used. The cooling water flows inside 50 copper tubes with a height of $1300 \mathrm{~mm}$ from the bottom upwards to the top. The 50 copper tubes provide a total surface area of $5.817 \mathrm{~m}^{2}$. Figure-4 illustrates the condenser dimensions. The air/water vapor mixture enters the top of the dehumidifier and flowing downward through the shell side. The condensed water during the operation is extracted from the bottom through a tube connected to the collecting tank. Two openings are provided at the shell side for the entering mixture at the top and the returning air at the bottom.

3) Heater: Humidifier bottom water is heated by using a heat exchanger with a total surface area of 11.074 $\mathrm{m}^{2}$, where hot oil flows through exposed pipes and transfers heat to the water. The heat exchanger used is for the automobiles, which is made from aluminum due to its relatively high availability and its very high thermal conductivity. Moreover, fins are used to conduct the heat from the tubes and transfer it to the water. The complete heating loop is illustrated in figure-1.The heating fluid is $10 \mathrm{~W}-30$ synthetic blend motor oil, which has high temperature oxidation and thickening for long-term use. The oil is heated in the oil storage tank with electrical heater, which is used to study the performance of the unit and mimics the renewable energy source. The electric heating loop controls the temperature by using a thermostat, which senses the temperature of the oil inside the tank and initiates control by switching the heater on or off. Oil set point temperature controlled by an operator in order to maintain the desired humidifier inlet water temperature. The oil circulation loop is driven by gear pump with a maximum flow capacity of $751 / \mathrm{min}$. 
4) Drives and Control system: There are four primary AC 220 drives in the desalination unit which are the cooling water pump, circulating water pump, oil pump and the air fan. The circulating water pump runs at full capacity during the experiment. The cooling water pump supplies the makeup and cooling water to the dehumidifier based on the desired flow capacity. The air fan and oil pumps flow capacities are varied based on the experiment plan. The flow capacities of the cooling water pump, oil pump and the air fan are controlled by adjusting their drives frequency. AC frequency inverter is used to alter the speed of the motor while maintaining the torque. Figure-5 illustrates the drives control loop.The frequency inverters are able to work with a variety of control systems and sensors. It allows controlling the motor's output in response to a control signal in order to achieve the required operating condition.
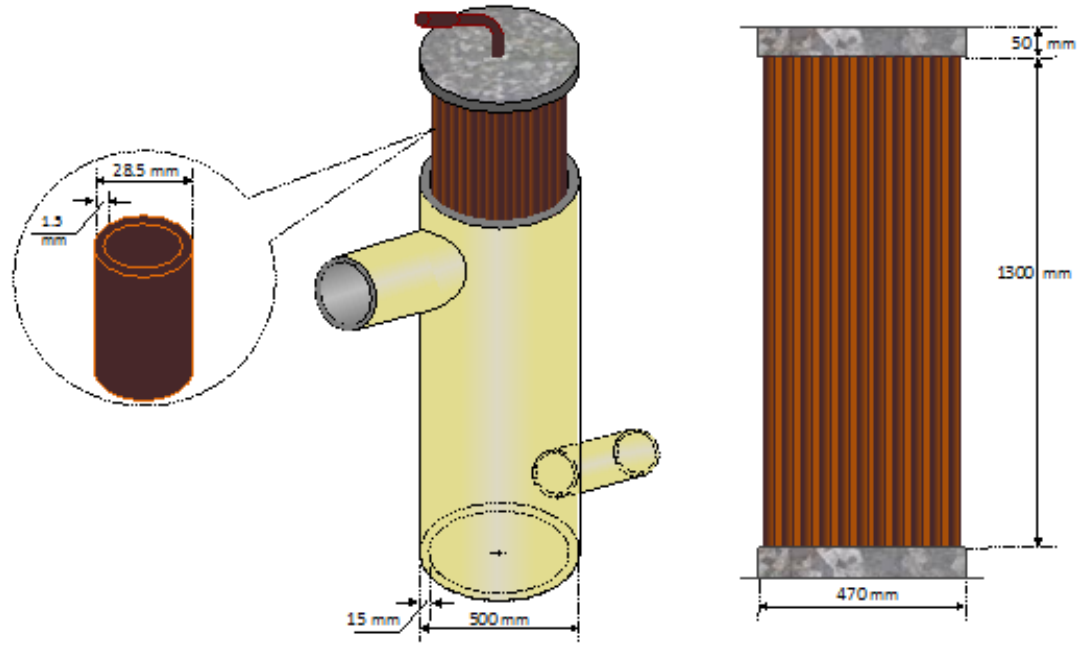

Fig. 4. Schematic diagram of the dehumidifier.

5) Measuring devices: The temperatures of the water, air and oil at different points are measured by usingtype $\mathrm{K}$ thermocouple (Nickel-Chromium/Nickel-Alumel) due to its accuracy, reliability, and has a wide temperature range. The layout of the sensors is illustrated in figure-1. The sensors wired to the local panel and connected to the field point thermocouple input module having eight different inputs with 16-bit resolution. The field point signals measured and linearized in the module then the scaled values return to the monitoring software through a direct connection to PC serial port. Air relative humidity (RH) measured by a scientific grade humidity sensors fitted in the air ducts with $+/-3 \%$ accuracy between $10 \%-90 \% \mathrm{RH}$. The produced water is collected hourly from the condenser and measured by a scaled container. A calibration process performed to measure air, water and oil flow rates. The data are tabulated in order to scale the drive frequency value with the drive output; hence the flow capacity is identified for each drive frequency set value.

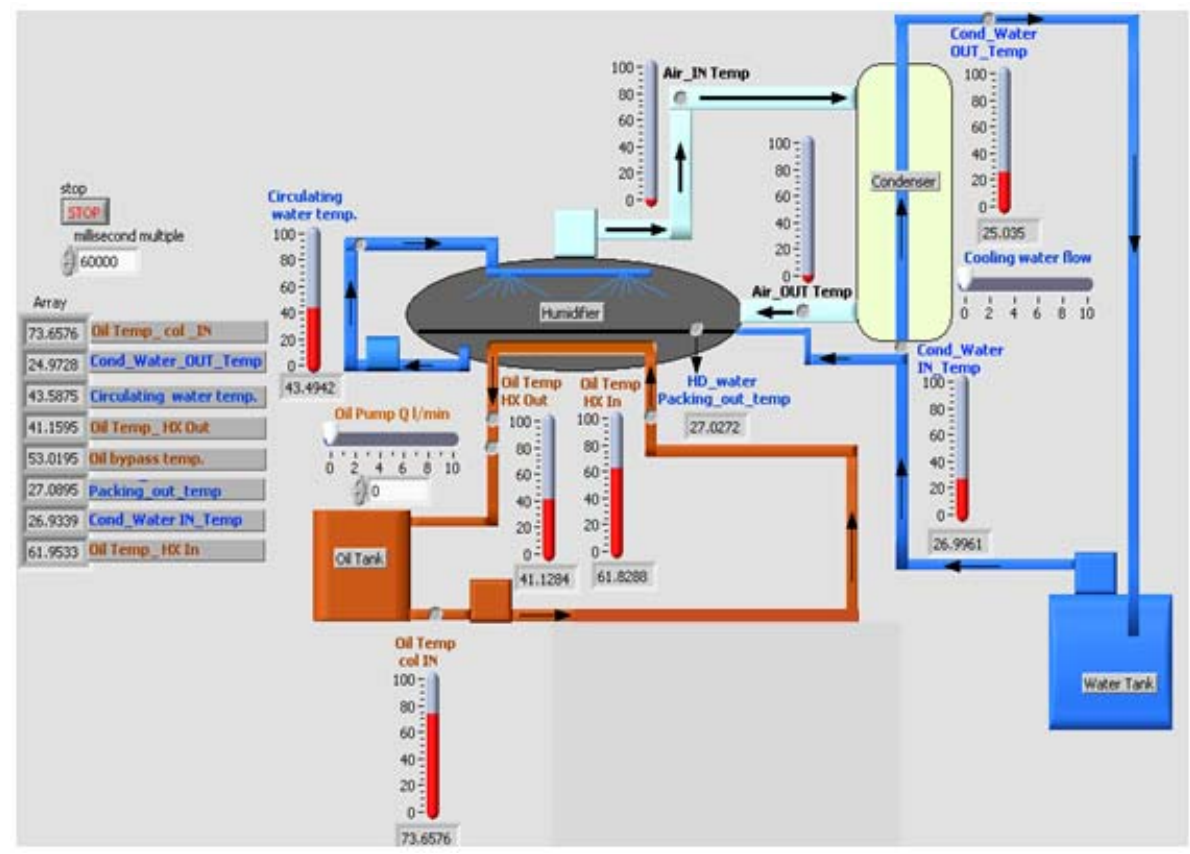

Fig. 5. Experiment graphical interface in labVIEW monitoring screen. 
In order to test, measure and control the process during the experiment, Laboratory Virtual Instrument Engineering Workbench (labVIEW) software is used. The data arranged with the graphical interface by visual programming language for easily visualizing and monitor the process as shown in figure-5.

\section{B. Experiment procedure}

In order to prepare the unit for the experiment, all drives started and set to the required flow rates. Circulation of the water around the humidifier is checked to make sure that the packing is completely wet. The oil heater unit to be started and set to control the oil temperature to reach the desired humidifier inlet water temperature. After the heating period, the unit is eligible for testing. When the experiment run started the data are collected from the monitoring screen. For a steady unit operation, all the data collected for a one-hour run. The produced water is collected, and the quantity is measured. When one experiment run is completed the drives frequency changed and set for different flow rates. Between each experiment runs the system adjusted, so it reaches the steady condition before start recording the data.

\section{Experiment analysis}

From the previous experiment procedure, the measured data are collected and tabulated. The humidity ratio and enthalpy for the circulating air between the humidifier and dehumidifier are calculated, from which the humidifier efficiency is obtained as follows:

$$
\eta_{H}=100 \times\left(\frac{\omega_{a 2}-\omega_{a 1}}{\omega_{s}-\omega_{a 1}}\right)
$$

Where $\omega_{a 1}, \omega_{a 2}$ are the humidifier inlet and outlet air humidity ratios and $\omega_{s}$ is the absolute air humidity at saturation.For obtaining the GOR, the heat rate to the humidifier is calculated from the mass and energy balance across the humidifier bottom, figure- 6 .

Mass balance

Energy balance

$$
m_{w 2}+m_{M U}=m_{w 1}
$$

$$
Q_{\text {in }}=m_{\text {oil }} c_{o i l}\left(\Delta T_{o i l}\right)=m_{w 2} c_{w} T_{w 2}+m_{M U} c_{w} T_{M U}-m_{w 1} c_{w} T_{w 1}
$$

Where

$$
m_{M U}=m_{a}\left(\omega_{a 2}-\omega_{a 1}\right)
$$

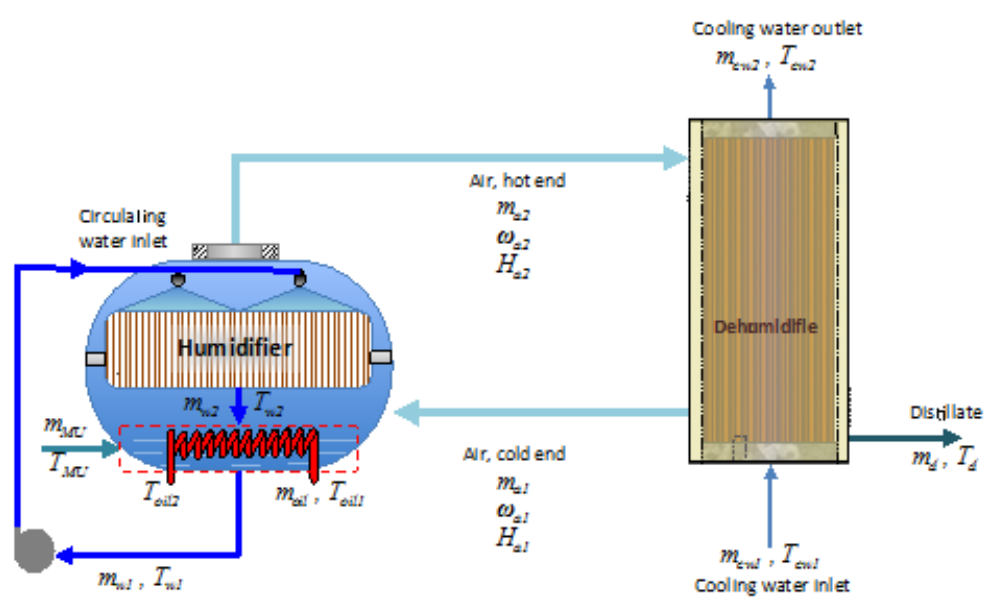

Fig. 6. Schematic of humidification and dehumidification desalination unit.

The GOR is the ratio of the latent heat of evaporation of the produced water at the ambient conditions to the net heat rate to the humidifier and can be calculated as:

$$
G O R=\frac{m_{d} h_{f g}}{Q_{\text {in }}}
$$

The mass transfer coefficient of the humidifier can be calculated by using Merkel Equation [19], [20]. The equation can be solved either graphically by Mickley [19] method or by the numerical integration.

$$
Z=\int_{T_{w 1}}^{T_{w 2}} \frac{m_{w} d T_{w}}{S K_{y} a\left(H_{i}-H\right)}
$$


The mathematician Chebyshev [20] used numerical integration method for solving the equation. This method compared to Jaber et al. [21] calculation using effectiveness- number of transfer units ( $\varepsilon$-NTU) method and showed no significant error [20], [21]. It was also shown that the log mean enthalpy difference (LMED) method is totally consistent with $\varepsilon$-NTU method [21], hence the flowing relation is used.

$$
m_{a}\left(H_{2}-H_{1}\right)=K_{y} a V \Delta H_{m}
$$

The $\log$ mean enthalpy difference is calculated as:

$$
\Delta H_{m}=\frac{\left(H_{a s 2}-H_{2}\right)-\left(H_{a s 1}-H_{1}\right)}{\ln \left(\frac{\left(H_{a s 2}-H_{2}\right)-f}{\left(H_{a s 1}-H_{1}\right)-f}\right)}
$$

Where $f$ is the developed analytical based correction factor and calculated as:

$$
f=\frac{H_{a s 1}+H_{a s 2}-2 H_{a v g}}{4}
$$

In order to calculate the overall heat transfer coefficient in the condenser an LMTED method [22] is used and applied across the condenser as shown in equation 10.

Where $\Delta T_{l m}$ is calculated as:

$$
m_{c w} c_{c w}\left(T_{c w 2}-T_{c w 1}\right)=U A_{D H} \Delta T_{l m}
$$

$$
\Delta T_{l m}=\frac{\left(T_{a 2}-T_{c w 2}\right)-\left(T_{a 1}-T_{c w 1}\right)}{\ln \left(\frac{\left(T_{a 2}-T_{c w 2}\right)}{\left(T_{a 1}-T_{c w 1}\right)}\right)}
$$

Thermodynamic relations are used to calculate the required streams properties. The absolute humidity is obtained by using the partial pressure of the water vapor in air [23].

$$
\omega=0.62 \frac{P_{v}}{P_{T}-P_{v}}
$$

Where $P_{T}$ is the total pressureand $P_{v}$ is the partial pressure of water vapor, which can be obtained by Antoine equation [24].

$$
\ln P_{v}=18.3036-\frac{3816.44}{227.02+T\left({ }^{\circ} \mathrm{C}\right)}
$$

The humid air enthalpy calculated by using the following relation [23].

$$
H_{a}=\left[c_{a} T_{a}+597.2 \omega\right] \times 4186.8
$$

Where $c_{a}$ is the specific heat of humid air [24] and can be calculated as:

$$
c_{a}=[0.24+0.46 \omega]
$$

From the previous equations and the data collected from the experiment, it was able to compute the absolute humidity and the enthalpy of the air at the inlet and outlet of the humidifier.

\section{RESULTS AND DISCUSSION}

The desalination unit operated at different mode of operation. Air flow rate increased gradually at constant humidifier inlet water temperature. This operation method repeated to study the effect of increasing air flow rate at different humidifier inlet water temperature. The humidifier inlet water temperature remained constant for each time air flow increased and studied.

\section{A. Effect of air flow rate}

The study exhibited the results of three humidifier inlet water temperatures, starting from 40 up to $50{ }^{\circ} \mathrm{C}$ with an increment of $5{ }^{\circ} \mathrm{C}$. Air mass flow rate increased to study the effect of that increase on the system productivity. Figure-7 illustrates the change of system productivity with air flow increase. The system shows an increase in the productivity by increasing air flow rate.This increase shows a good agreement with basic principal of having the increased amount of air carrying more water vapor to the dehumidifier. Based on that, the absolute humidity of the air leaving the humidifier was higher as air flow rate increased. The productivity of the system at humidifier inlet water temperature at 40 and $45^{\circ} \mathrm{C}$ shows a decline as air flow rate increase due to the reduction in absolute humidity difference, hence it is preferred to promote the absolute humidity difference by increasing the inlet water temperature.

\section{B. Effect of humidifier inlet water temperature}

It was observed that increasing humidifier inlet water temperature has a significant influence on increasing the system productivity for all different air flow rates. Figure-8 illustrates the productivity of the system when inlet water temperature increased. When increasing the humidifier inlet water temperature more sensible heat is transferred from the water. Also, the increase of inlet water temperature leads to an increase of water vaporization, hence more water vapor transferred despite the type or the shape of the humidifier packing. 


\section{Gained output ratio (GOR)}

More energy in the humidifier inlet water would increase the GOR. Figure-9 shows the influence of higher inlet water temperature with increasing air flow rate. The GOR of the system increases with increasing air flow rate. The more air flow rate contributing to having this increase in GOR, due to the increase of vapor transport with air to the dehumidifier. The forced air circulation increases the productivity and enhances the saving in the required input heat.

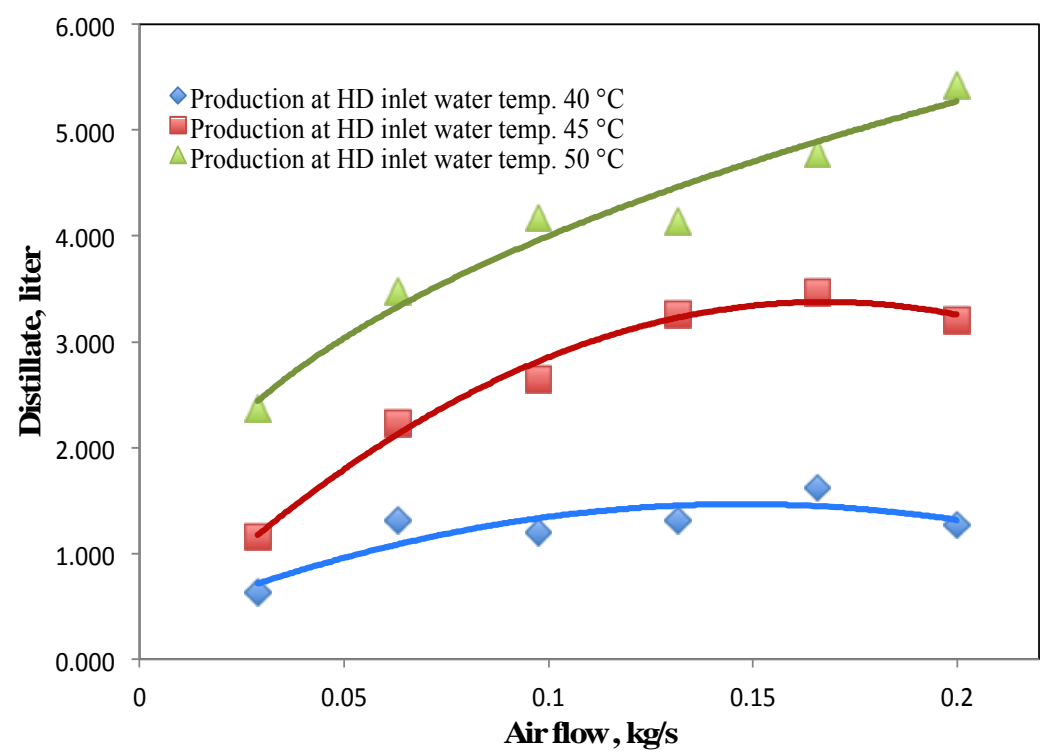

Fig. 7. Effect of air flow increase on the system productivity.

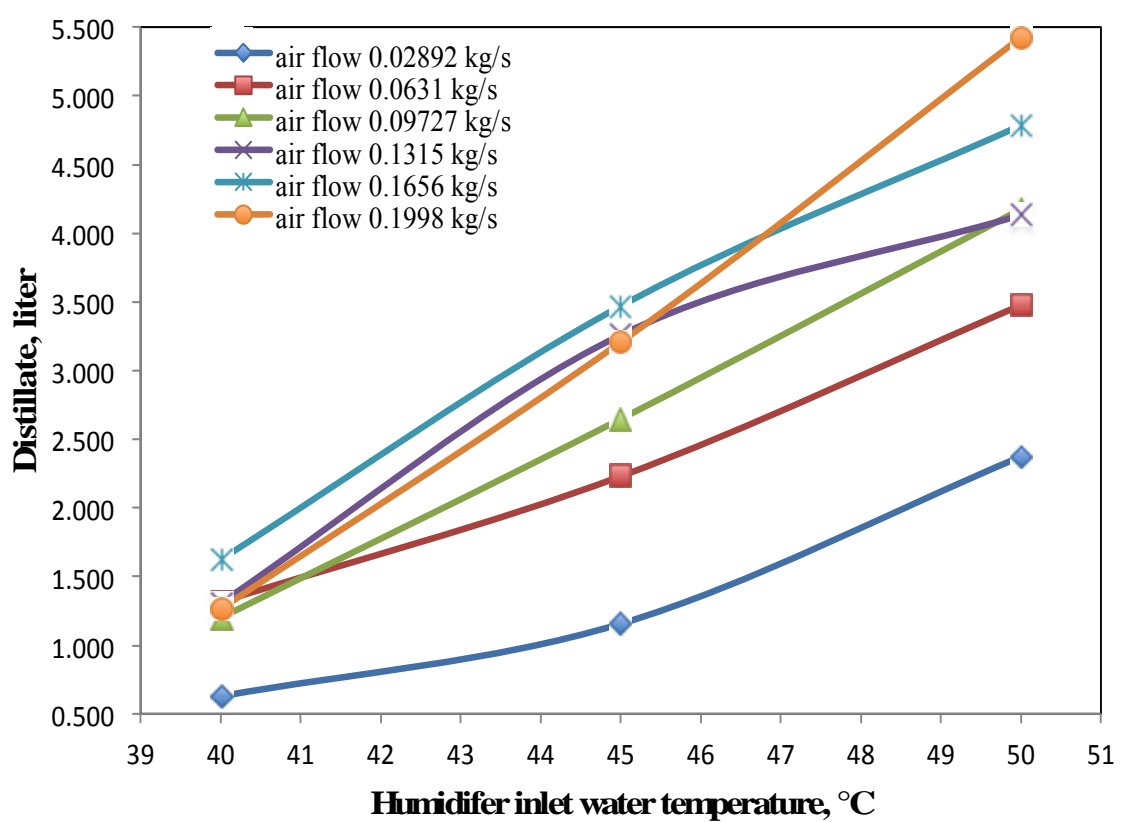

Fig. 8. Effect of HD inlet water temperature on the system productivity. 


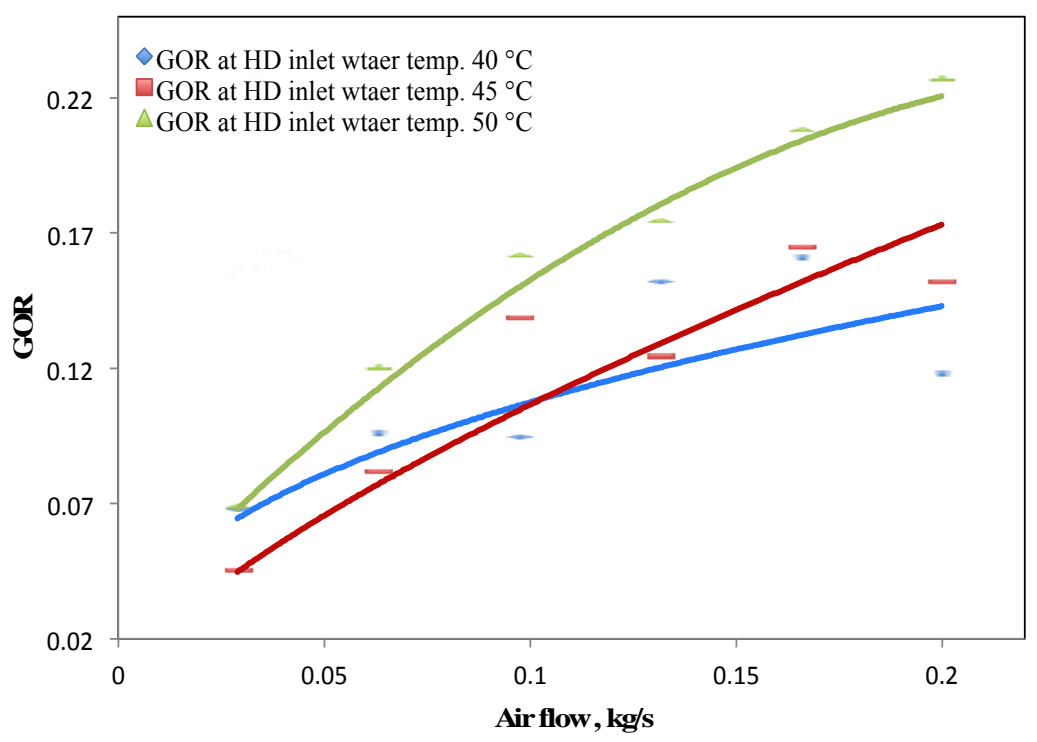

Fig. 9. GOR at different air flow rate.

Moreover, the absolute humidity difference of the system decreases as the air flow rate increased as shown in figure-10. Such a humidification and dehumidification desalination process depends on the thermodynamic characteristic of high humidity air flowing through the process. The heating-humidifying procedure will increase the absolute humidity of the humidifier outlet stream, and by increasing the air flow rate, this will lead to more water vapor entrained in the humidifier outlet stream and forwarded to the dehumidifier which increases the system productivity.

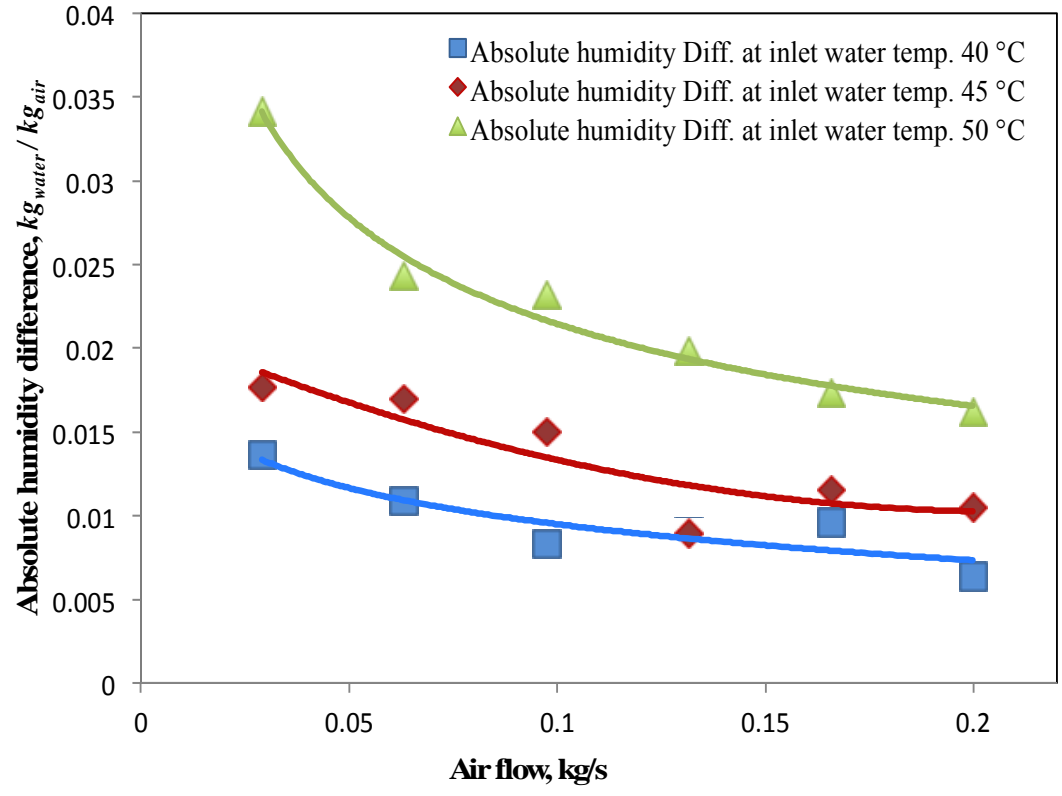

Fig. 10. Absolute humidity difference at different air flow rate.

\section{Humidifier efficiency and enthalpy difference}

Higher air flow rate decreases the humidification process due to less residence time of carrier air which reduces the humidity of air coming out from the humidifier, hence, when air flow rate is too high, the humidifier efficiency will fall. Figure-11 shows the effect of air flow rate on humidifier efficiency. The efficiency of the system has no significant change when the inlet water temperature is $40{ }^{\circ} \mathrm{C}$, as the water has lower sensible heat compared to higher temperatures of 45 and $50{ }^{\circ} \mathrm{C}$. The efficiency is obviously increasing as the inlet water increased and declining with further air flow rate increase. 


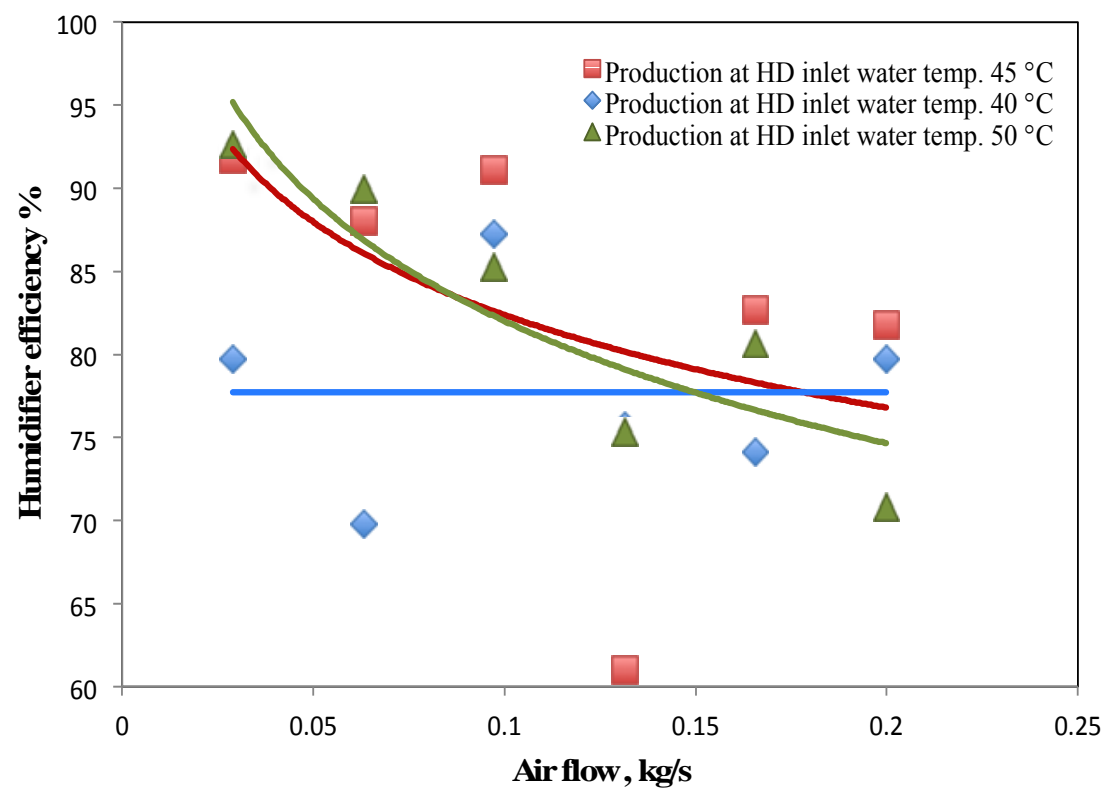

Fig. 11. The change in humidifier efficiency with air flow rate.

Figure 12 shows the cooling effect of higher air flow rates which decrease the enthalpy difference between the incoming and the rising air. Although, the inlet water temperature has a good influence on the enthalpy difference, the air flow increase can positively affect the unit productivity while decreasing the enthalpy difference of the system.

The productivity of the system at inlet water temperature 40 and $45{ }^{\circ} \mathrm{C}$ is affected by the enthalpy reduction while the $50{ }^{\circ} \mathrm{C}$ stream still increasing. The process is more favorable towards increasing the inlet water temperature,air flow rate and further optimization is required.The system productivity enhanced as long as the overall driving force representing the enthalpy difference for bulk air is increased. Consequently, the warm air in contact with hot water so the humidity of the air is less than that at the air-water interface,hence, water vapor will vaporize toward the air and will be humidified. It would be necessary to address such an increase of the air flow rate to ensure maximum GOR and reduce the suppress of the absolute humidity and the enthalpy difference for the system.

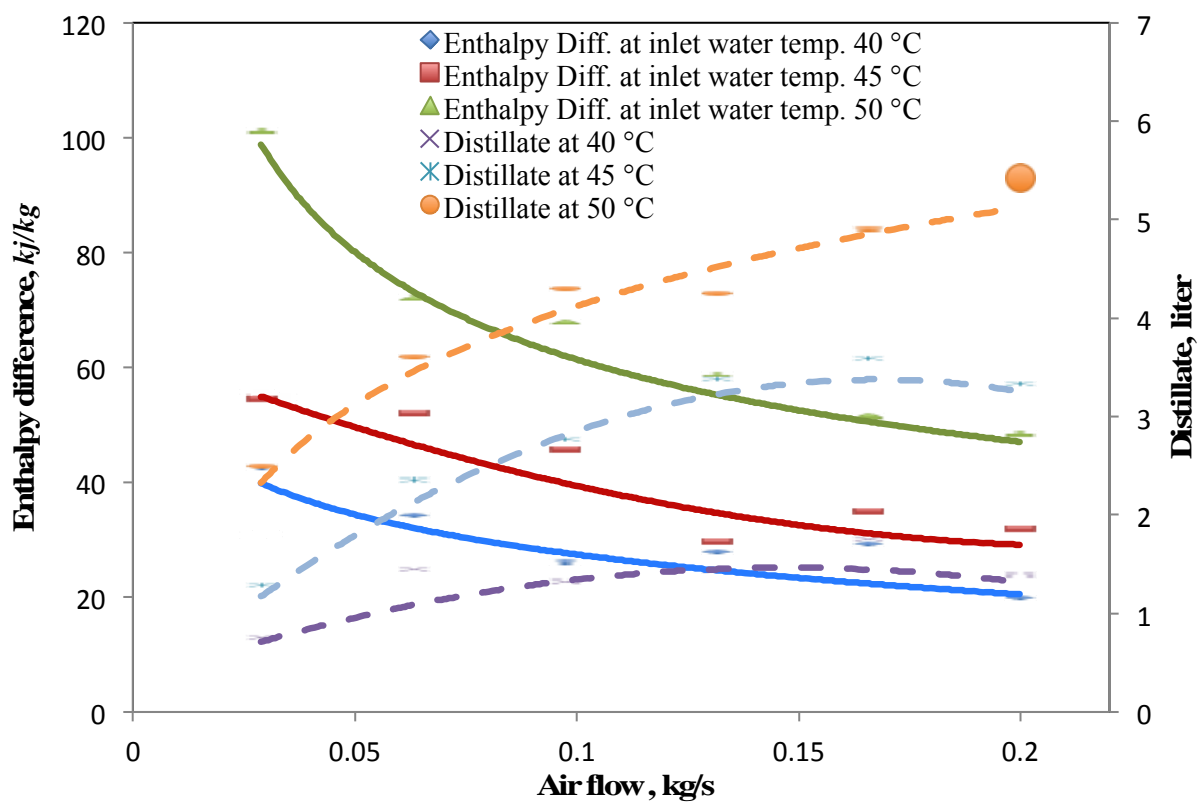

Fig. 12. The change in enthalpy difference, productivity with air flow rate. 


\section{E. Mass transfer and overall heat transfer coefficient}

Increasing the air flow rate increases the mass transfer coefficient by increasing the amount of water vapor entrained by air. Figure 13 shows that the characteristics of the humidifier during air flow rate increase at different inlet water temperatures. Moreover, the coefficients are shown to be relatively less effected by increasing the inlet water temperature. The increase or decrease in wet-bulb temperature of entering water does not have a great influence on the humidifier characteristics. Only the inlet water flow rate, air flow rate, mass transfer area and the volume are the major variables that attributed to affecting the humidifier characteristics. This is represented in Merkel Equation(6).

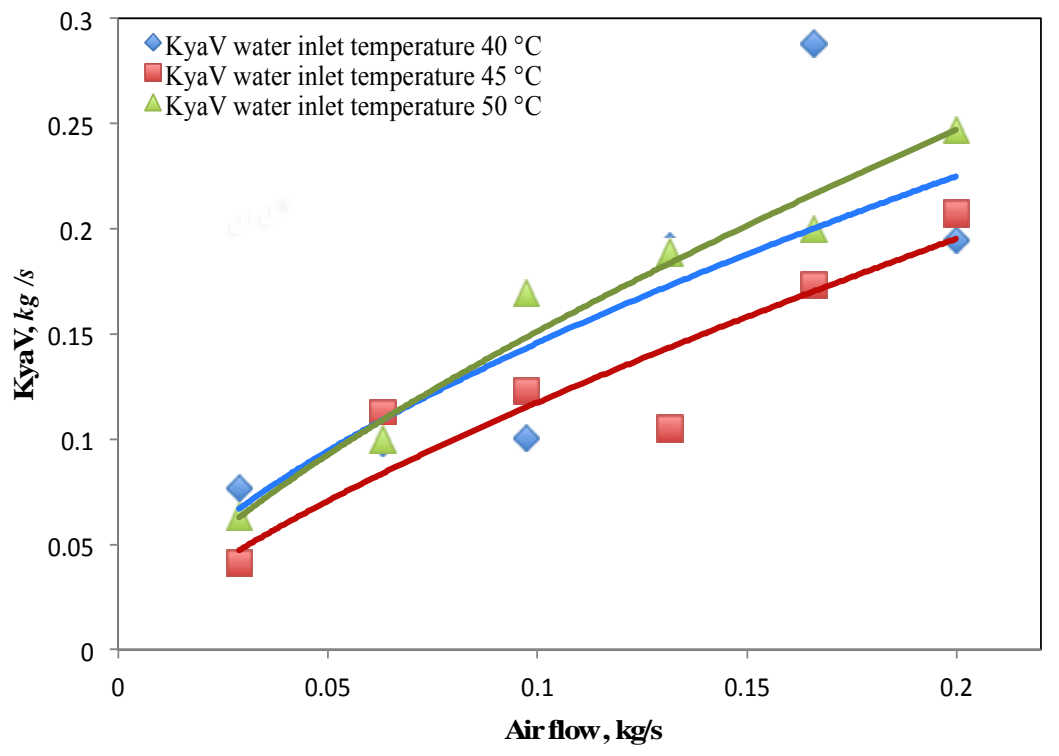

Fig. 13. Effect of air flow increase on the Mass transfer coefficient.

Furthermore, the mass transfer coefficients are obtained experimentally where the humidified air operates near the saturation line. For the present system, the mass transfer coefficients are recalculated assuming the air leaving the humidifier and returning at the curve marked $100 \%$ saturated air in the humidity curve. This consideration is more practical when the packing and spray nozzles are highly efficient, hence the efficiency of contact between air and water in terms of volumetric mass transfer coefficient $K_{y} a V$ is improved. Figure 14 shows the difference between the mass transfer coefficients when the system operates at the saturation curve and the experiment condition. Higher mass transfer coefficient is obtained as long as air flow rate increases at saturation condition when compared with the calculated coefficient from the experiment. The results are helpful so the coefficients can be used for further simulation work. For the dehumidifier, the overall heat transfer coefficient obtained by applying overall energy balances to the hot and cold fluids. The calculation assumes negligible heat transfer between the exchanger and the surroundings, also negligible potential and kinetic energy changes. In fact, the overall heat transfer coefficient changes due to alterations in air flow rates and inlet air temperature.

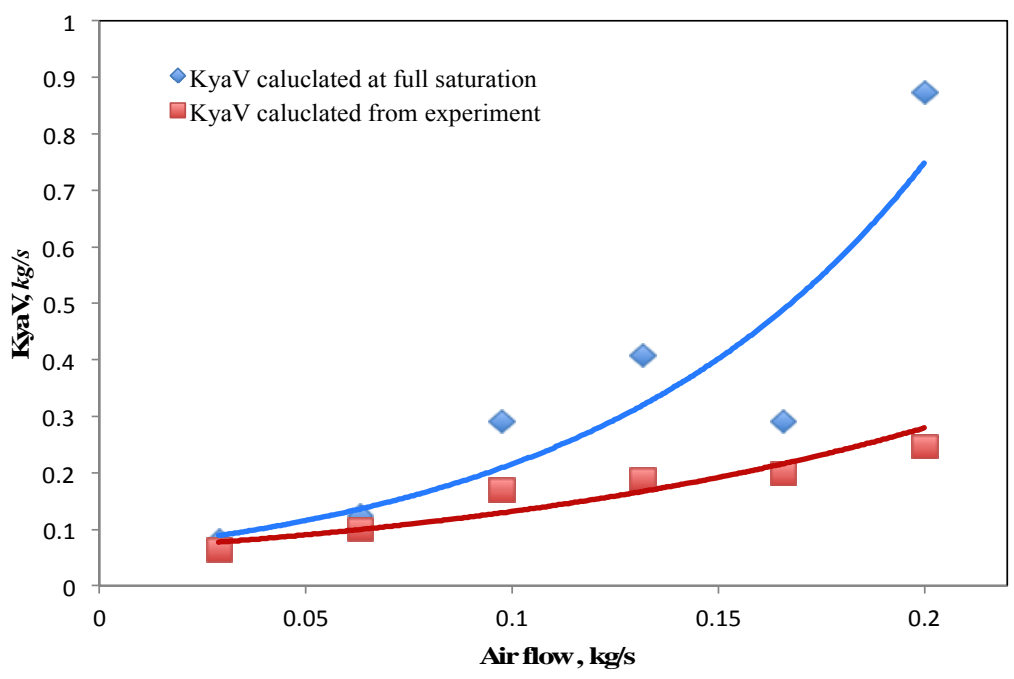

Fig. 14 Experimental mass transfer coefficient $v s$ full saturation condition. 
In the present condition, air flow rate increased each run while humidifier inlet water flow rate and its temperature are constant. Figure 15 provides the relation between the increase of circulating air in the system and the increase of the dehumidifier overall heat transfer coefficient. Increasing air flow rate has a significant influence on the dehumidifier overall heat transfer coefficient increase for the specified total heat transfer surface area.

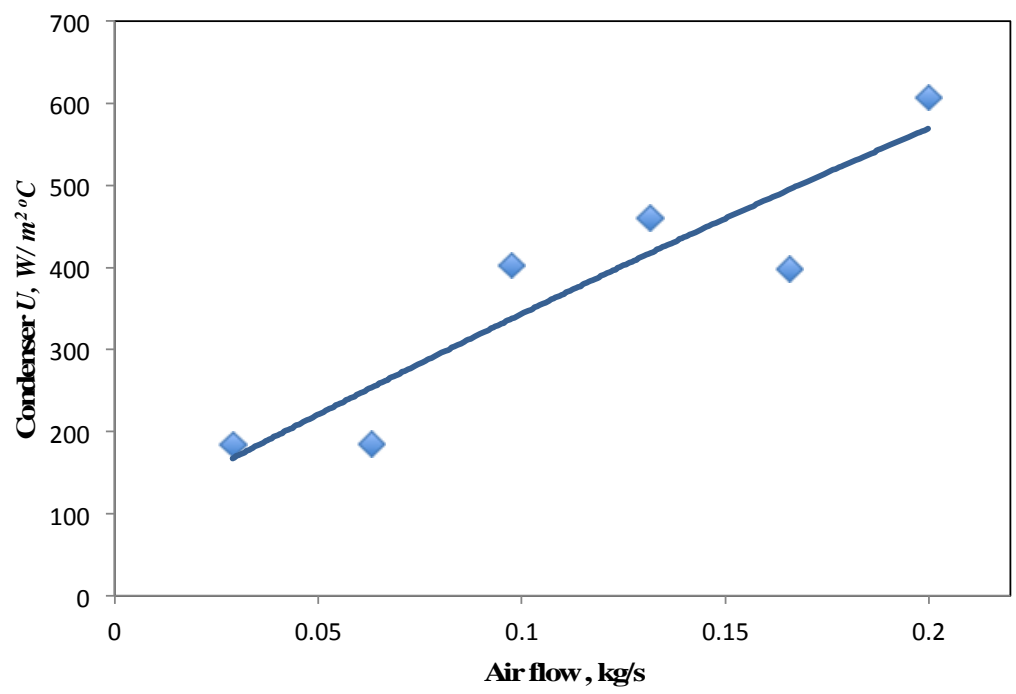

Fig. 15Dehumidifier overall heat transfer coefficient.

The experimental mass transfer coefficient is correlated and given by the following equation. With the coefficient of determination is $R^{2}=0.97513$. The correlation is valid for the experiment operating range

$$
K_{y} a V=0.5195\left(\frac{m_{w 1}}{m_{a}}\right)^{-0.708}
$$

\section{ECONOMIC ANALYSIS}

In order to evaluate the economics of the designed HDH desalination system, an annualized cost method is used [25]. The production cost can be the summation of both fixed and variable production costs. Comparing the value of the variable cost with the fixed cost, the fixed cost usually much less than the variable cost [25]; hence, only the variable cost calculated. The variable production cost depends on the production rate of the system and includes the consumed energy for heating, operating drives, and the cooling power. The maintenance cost $\left(C_{M}\right)$ taken as $3 \%$ of the capital cost [25]. The uniform cash flow of cost at a constant rate calculated for the system representing the annual capital charge [26]. For the present HDH system if the capital $\operatorname{cost}(P)$ invested at an interest rate $(i)$ of $5 \%$ for $(n) 20$ years, the capital recovery is obtained as follows [26]:

$$
\text { Annual capital cost }\left(C_{A}\right)=P \frac{\left[i(1+i)^{n}\right]}{\left[(1+i)^{n}-1\right]}
$$

The operating cost obtained $\left(C_{O P}\right)$ by adding the energy used by the system and the required power for the drives and controls then evaluated based on the local power price. The total cost of production includes the annual capital cost, maintenance cost, and the total operating cost is calculated by the following relation [27].

$$
C_{T O P}=C_{A}+C_{O P}+C_{M}
$$

The plant operates throughout the year with availability factor taken of $90 \%$. Since the drives provided with frequency inverters which have a provision for power record, it was possible to monitor the power consumed for each experiment runs. The energy consumed by the heater at the bottom of the humidifier calculated by using equation number (3). The electrical power $(\mathrm{kWh})$ cost in the kingdom of Saudi Arabia for the industrial grade is about $0.048 \mathrm{US} \$ \mathrm{kWh}[28]$. The designed HDH unit incorporated with an electrical heater and also can couple with a solar energy source for further cost reduction. The initial investment $P$ that required for the HDH system provided in table-1. The production cost estimated based on the previous data by the following relation.

$$
\text { Production cost }=\frac{\text { Total production } \operatorname{cost}\left(C_{T O P}\right)}{\text { Annual production }} \frac{U S \$}{\mathrm{~m}^{3}}
$$


TABLE I. CAPITAL COST OF THE HDH UNIT

\begin{tabular}{|l|lc|}
\hline Description & \multicolumn{2}{|c|}{ Cost } \\
\hline Humidifier vessel & 200 & US\$ \\
\hline Dehumidifier (heat exchanger) with $5.82 \mathrm{~m} 2$ area & 1,000 & US\$ \\
\hline Blower & 150 & US\$ \\
\hline Circulating water pump & 50 & US\$ \\
\hline Cooling water pump & 150 & US\$ \\
\hline Oil pump & 300 & US\$ \\
\hline Packing & 50 & US\$ \\
\hline Piping and fittings & 300 & US\$ \\
\hline Control unit and sensors & 750 & US\$ \\
\hline Oil heating equipment & 300 & US\$ \\
\hline Oil tank & 50 & US\$ \\
\hline Installation \& fabrication & 500 & US\$ \\
\hline Humidifier heat exchanger & 200 & US\$ \\
\hline HDH Capital cost $(\boldsymbol{P})$ & $\mathbf{4 0 0 0}$ & US\$ \\
\hline
\end{tabular}

Many other factors can influence predicting the production cost such as land, buildings, and country regulations and others, hence, the following considerations are assumed in the analysis.

1. The cost of production does not include other processes such as pre or post treatments.

2. Fixed operating cost is less when compared with the variable operating cost and it may vary based on the administrative policy, therefore it is not included in the calculation.

3. Land and buildings are not included in the capital cost as they depend on the location and real state pricing within the region.

4. The cost calculated based on Saudi Arabia local market prices and the present currency exchange 3.75 SR/1US\$.

The cost analysis can be used together with the unit GOR and productivity to study the unit economics feasibility. The optimum value of air flow rate can be selected to obtain the best results of maximum productivity and highest system GOR at the lowest possible production cost. Figure-16 shows the trade-off between GOR, water productivity and the production cost at different air flow rates. This plot is generated at various humidifier inlet water temperatures to find out the optimum systemproductivity and GOR at the desired air flow rate for the present condition of inlet water temperature. The optimum GOR for the system ranges between 0.13 and 0.22 while increasing the inlet water temperature shown to improve the GOR. The maximum GOR values correspond to air flow rates ranges between 0.158 up to $0.2 \mathrm{~kg} / \mathrm{s}$, while the optimum predicted production cost varies between 0.043 to $0.09 \mathrm{US} \$$ /liter. The best results obtained at high HD inlet water temperature at the maximum tested air flow rate where the GOR obtained is 0.22 for the production cost of $0.043 \mathrm{US} \$$ /liter. The acquired production cost increases at lower inlet HD water temperatures and lower air flow rate, this attributed to the weaker recovery compared to the energy used. The maximum system GOR allows for less energy requirement; this will help in the reduction of the size of solar heater area or any other energy source. By reducing the size and required energy for the system, consequently, the capital and running cost will decrease. 


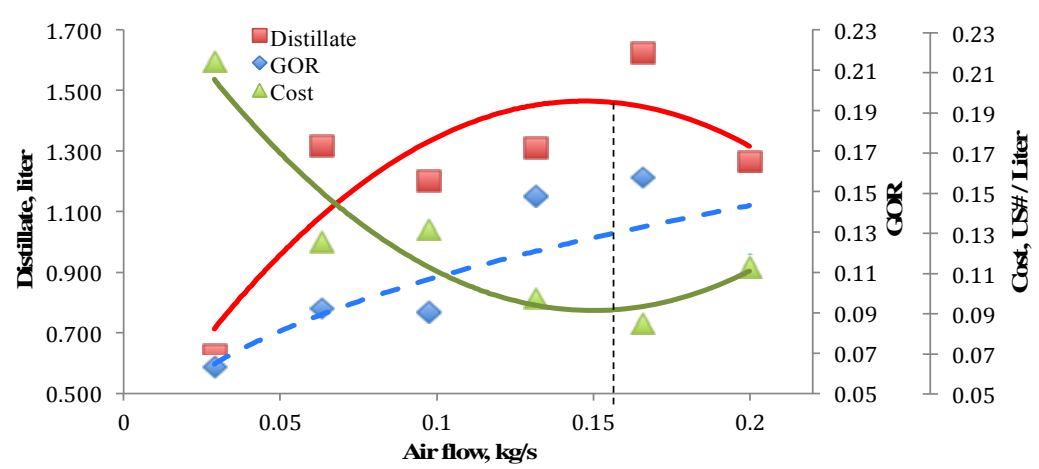

(a) Trend for HD inlet water at $40{ }^{\circ} \mathrm{C}$

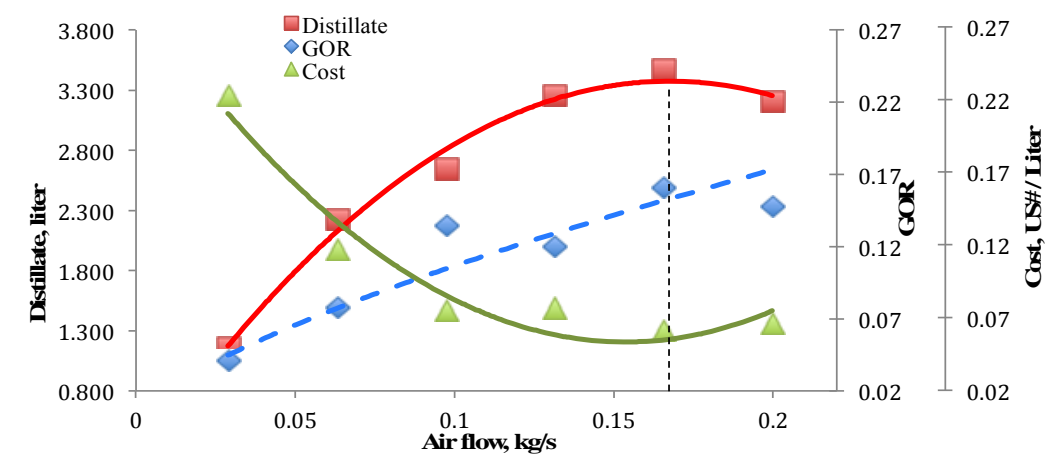

(b) Trend for $\mathrm{HD}$ inlet water at $45^{\circ} \mathrm{C}$

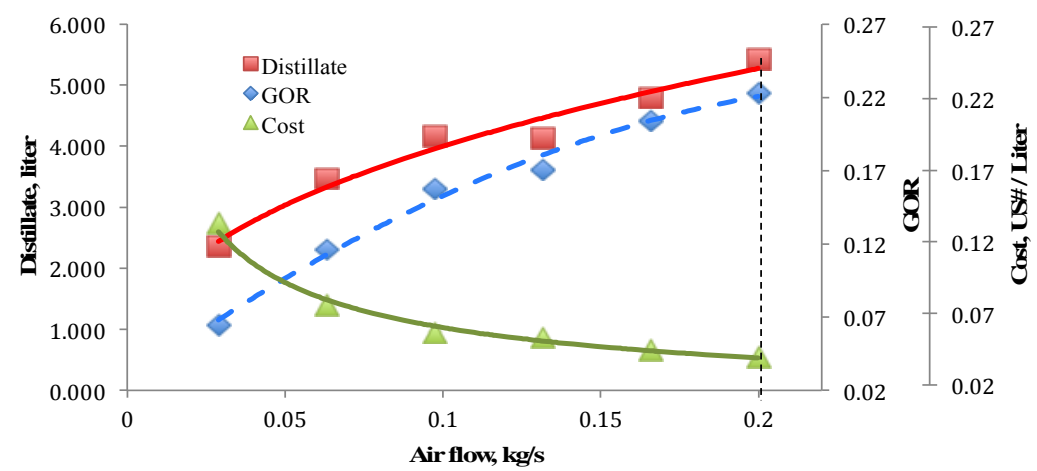

(c) Trend for HD inlet water at $50^{\circ} \mathrm{C}$

Fig. $16 \mathrm{GOR}$, production cost and productivity at different air flow rate.

Figure 17 is the regenerated plot of the optimum values for the GOR, the system productivity, and the operation cost. The scheme gives the best-required air flow rate at different inlet water conditions which fit the optimum designed system of humidification and dehumidification desalination process.

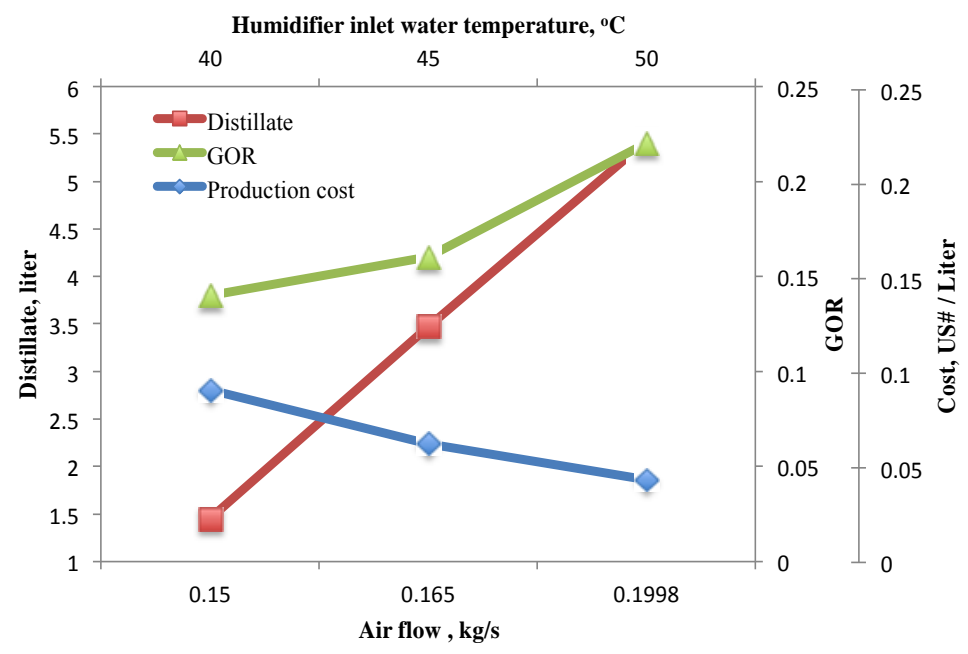

Fig. 17Optimum GOR, production cost and productivity for the system. 


\section{FEATURES OF THE SYSTEM}

The makeup water is added to the recirculation system in the humidifier bottom, to replace the vapor entrained in the air. The maximum estimated vapor transfer by humidification is $0.264 \%$ of the recirculation rate for such an induced draft humidifier. When the desalination system uses high salinity water, a continuous blowdown can be provided to maintain the system salinity in the humidifier. The blowdown estimated as $60 \%$ of the vapor lost by the humidification procedure, therefore, the maximum make up for the HDH system is $0.423 \%$ of the recirculation rate, hence; it does not significantly influence the required heating energy. The process also does not need a sophisticated water treatment concerning using antiscalant, since the process works at lower top water temperature than other thermal desalination systems.

The advantage of the present system that the air circulation is in a closed loop as well as the water circulation in the humidifier. In this arrangement, the energy used is well preserved as possible to minimize the losses and the amount of heating requirement. The energy losses in the system considered mainly at the dehumidifier cooling process, as a good quality insulation material can reduce the other losses.

In this system the air leaving the humidifier and recirculates to enter the humidifier at a relative humidity near the saturation line, figure 18 illustrates the relative humidity of the system at different temperatures in the psychometric chart. The system operates at high relative humidity; hence water heating process is the crucial factor for increasing its performance.

The humidifier incorporated with a heat exchanger at the bottom side this will enhance a minimum loss of energy and make it possible to use either engine oil as used in this experiment or other thermal fluids for heating when coupled with solar heater. Energy saving is potential in this design as it could use both solar and electrical soure to increace the cvetem temnerature at lnxwect noccihle soct

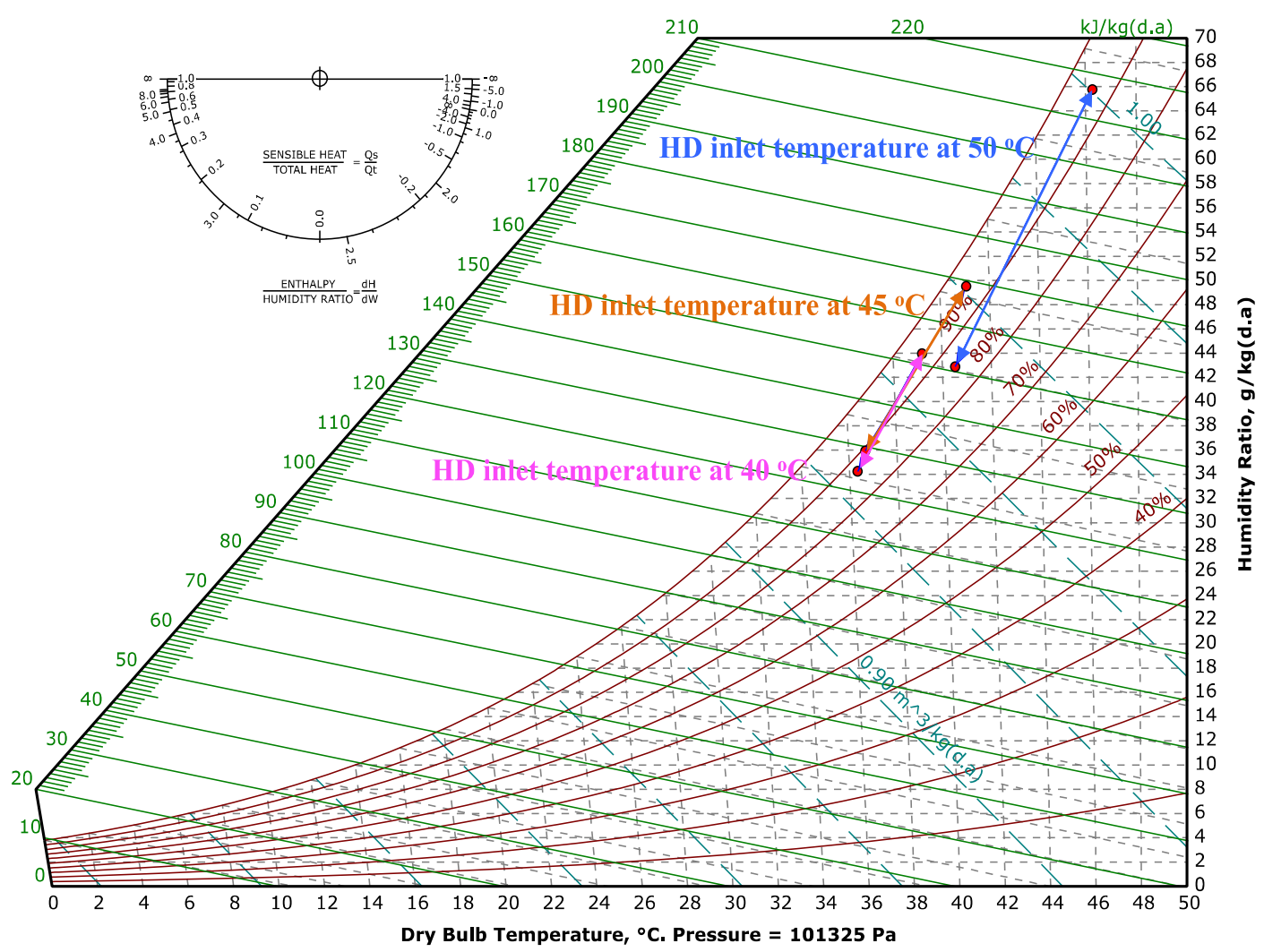

Fig. 18 Optimum GOR, production cost and productivity for the system.

Solar air heaters and open loop water heaters are less efficient when compared to the present design as the oil or the thermal fluids operates in a closed loop, which allows more sustained heat gain from the received irradiance. Oil temperature can increase above $100{ }^{\circ} \mathrm{C}$, without scale formation or oxidation, which allows more energy gain from the solar system. Figure-19 shows the average oil inlet and outlet temperatures from the humidifier heat exchanger at different inlet water temperatures. 


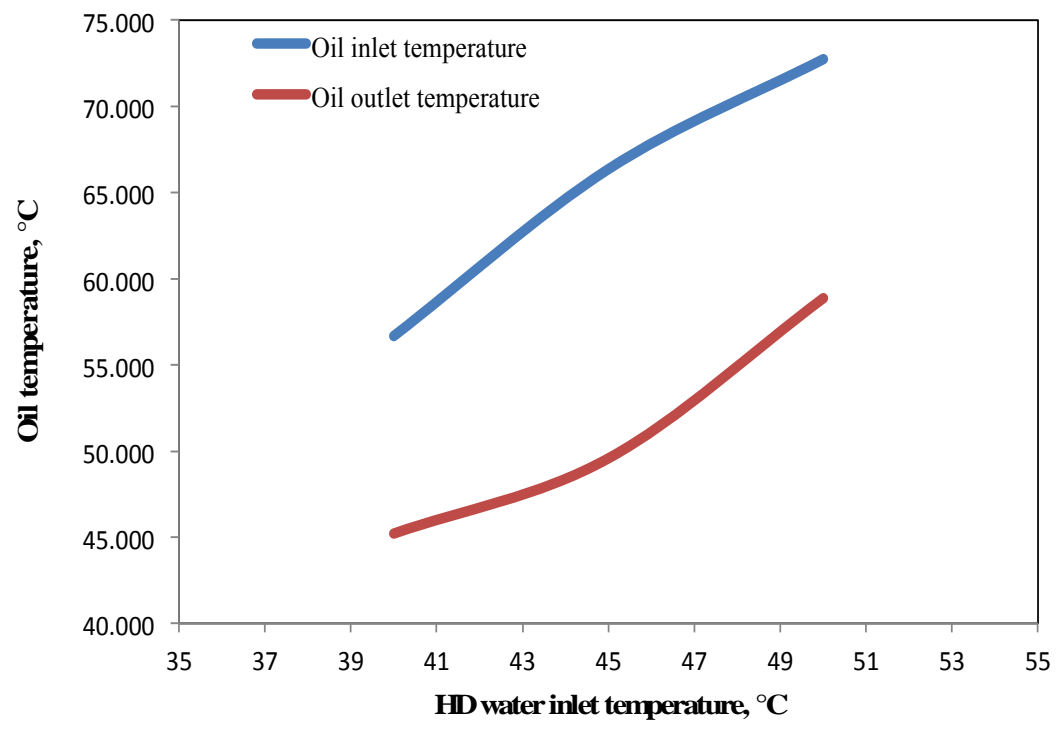

Fig. 19 HD oil inlet and outlet temperature at different water temperatures.

The continuous circulation process gives more flexibility regarding high heating capability obtained in the system with continuous water circulation in the humidifier. Input heat can modulate as required by changing the flow rate of the oil in the system.

Generally, for this design, the production cost found to be reduced as the circulating air flow rate increased. The reduction in the cost attributed to the improved vapor transfer at higher relative humidity with air towards the dehumidifier, which increases the unit yield. The other significant observation was the increase of the GOR as the recirculating air flow rate increased, which reduces the process demand for heating and optimization was a beneficial tool to obtain the best-operating conditions.

\section{CONCLUSION}

Humidification and dehumidification desalination experimental study performed to analyze the influence of different variables, which affect the system productivity during its operation. The system designed and configured by using simple available materials, which allows easy build of the system components. The conclusions obtained from the study presented here are the follows:

- Operating conditions such as air flow rate and humidifier inlet water temperature have a great positive influence on the system productivity. The results show that absolute humidity of the air leaving the humidifier was higher as air flow rate increased. This increase promoted at higher inlet water temperatures, which reveals higher productivity of $5.424 \mathrm{l} / \mathrm{hr}$ at $50{ }^{\circ} \mathrm{C}$ inlet water temperature.

- The system GOR is improved at higher inlet water temperatures and positively affected by increasing the air flow rates which will enhance the heating and humidifying process. Optimum values of the increased air flow rate are obtained for both best GOR, operating cost and maximum productivity. The best optimum system output obtained when the system GOR is 0.22 and production cost of 0.043 US $\$$ liter.

- When the air flow rate is too high, the humidifier efficiency will fall. Hence the enthalpy difference across the humidifier also decreases. It would improve by increasing the humidifier inlet water temperature.

- The humidifier mass transfer coefficient increased as long as air flow rate increased, this attributed to the enormous influence of air/water flow ratio which alters the process significantly compared to the change in the inlet water temperatures. The calculated mass transfer coefficient where air at the saturation curve reveals higher coefficients than the obtained from the experiment. Furthermore, dehumidifier overall heat transfer coefficient improved as air flow rate increased.

- Increasing the air flow rate provides a reduction in the production cost and positively affect the GOR of the desalination unit.

The study provides the HDH desalination system design at Jeddah city and layout the data for future work when the system coupled with a renewable energy sourceusing the heating fluid (10W-30) synthetic blend motor oil as the heating medium for better economical impact. 


\section{ACKNOWLEDGMENT}

This project was funded by the National Plan for Science, Technology and Innovation (MAARIFAH) - King Abdulaziz City for Science and Technology - the Kingdom of Saudi Arabia - award number (11-ENE2004-03). The authors also acknowledge with thanks, Science and Technology Unit, King Abdulaziz University for their technical support. The authors acknowledge the great support Dr.AbdulsalamAlghamdy head of King Salman Energy chair in accommodating the project installation into their premises.

\section{REFERENCES}

[1] El-Halwagi, M. M., "A Shortcut Approach to the Design of Once-Through Multi-Stage Flash Desalination Systems", Desalination and Water Treatment, 62,pp. 43-56, 2017.

[2] Zhao, Dongfeng, et al. "A lab-scale MED dealing with salinity wastewater: the study of optimal operation schemes and parameters", Desalination and Water Treatment 57.25, pp.11721-11728, 2016.

[3] Thirugnanasambandham, K., V. Sivakumar, and K. Shine. "Optimization of reverse osmosis treatment process to reuse the distillery wastewater using Taguchi design." Desalination and Water Treatment 57.51, pp. 24222-24230,2016.

[4] Ludwig, Heinz. "Energy consumption of reverse osmosis seawater desalination-possibilities for its optimization in design and operation of SWRO plants." Desalination and Water Treatment 13.1-3, pp. 13-25,2010.

[5] S.A. El-Agouz, A new process of desalination by air passing through seawater based on humidification de-humidification process, Energy 35, pp. 5108-5114, 2010.

[6] Y.J. Dai, H.F. Zhang, Experimental investigation of a solar desalination unit with humidification and dehumidification, Desalination 130, pp.169-175, 2000.

[7] Huifang Kang, Teng Wang, HongfeiZheng, Comparative analysis of regenerative and air-extraction multi stage humidificationdehumidification desalination system using pinch technology, Desalination 385, pp.158-166,2016.

[8] A.H. El-Shazly, A.A. Al-Zahrani, Y.A. Alhamed, S.A. Nosier, Productivity intensification of humidification-dehumidification desalination unit byusing pulsed water flow regime, Desalination 293, pp. 53-60, 2012.

[9] G. Prakash Narayan, Maximus G. St. John, Syed M. Zubair, John H. Lienhard, Thermal design of the humidification dehumidification desalination system: An experimental investigation, International Journal of Heat and Mass Transfer 58, pp. 740-748, 2013.

[10] Cheng Huaigang, Wang Shichang, Modelling and Experimental Investigation of Humidification-Dehumidification Desalination Using a Carbon-Filled-Plastic Shell-Tube column, Chin. J. Chem. Eng., 15(4), pp. 478-485, 2007.

[11] Mahmoud Ben Amara, ImedHoucine, AmenallahGuizani, Mohammed Maalej, Experimental study of a multiple-effect humidification solar desalination technique, Desalination 170, pp. 209-221, 2004.

[12] CemilYamal, Ismail Solmus, A solar desalination system using humidification-dehumidification process: experimental study and comparison with the theoretical results, Desalination, 220, pp. 538-551, 2008.

[13] J. Orfi, M. Laplante, H. Marmouch, N. Galanis, B. Benhamou, S. Ben Nasrallah and C.T. Nguyen, Experimental and theoretical study of a humidification-dehumidification water desalination system using solar energy, Desalination, 168, pp. 151-159, 2004.

[14] FarhadNematollahi, Amir Rahimi ,TourajTavakoliGheinani, Experimental and theoretical energy and exergy analysis for a solar desalination system, Desalination 317, pp. 23-31, 2013.

[15] Guofeng Yuan, Zhifeng Wang, Hongyong Li, Xing Li, Experimental study of a solar desalination system based on humidificationdehumidification process, Desalination 277, pp. 92-98, 2011.

[16] E.H. Amer, H. Kotb, G.H. Mostafa, A.R. El-Ghalban, Theoretical and experimental investigation of humidification-dehumidification desalination unit, Desalination 249, pp. 949-959, 2009.

[17] A.S. Nafey, H.E.S. Fath, S.O. El-Helaby, A. Soliman, Solar desalination using humidification-dehumidification processes Part II. An experimental investigation, Energy Conversion and Management 45, pp.1263-1277, 2004.

[18] Mahmoud M. El-Halwagi, A Return on Investment Metric for Incorporating Sustainability in Process Integration and Improvement Projects, Clean Technologies and Environmental Policy, 19, pp. 611-617, 2017.

[19] Coulson J. M., Richardson J. F., Coulson \& Richardson's Chemical Engineering, Fluid Flow, Heat Transfer and Mass Transfer, Sixth Edition, Oxford, UK: Butterworth-Heinemann, 1999,Vol. 1.

[20] Kröger, Detlev G., Air-Cooled Heat Exchangers and Cooling Towers. Thermal-Flow Performance Evaluation and Design, USA: PennWell Corporation, 2004, vol. 1.

[21] H. Jaber and B. L. Webb, Design of Cooling Towers by the Effectiveness-NTU Method, ASME Journal of Heat Transfer Vol. 111, pp. 837- 843, Nov1989.

[22] Frank P. Incropera, David P. Dewitt, Theodore L. Bergman and Adrienne S. Lavine, Fundamentals of Heat and Mass Transfer, Sixth edition, John Wiley \& Sons, 2007.

[23] Y. A. Çengel and M. A. Boles, Thermodynamics: An Engineering Approach, 5th ed, McGraw-Hill, 2006.

[24] R. K. Sinnott, Chemical Engineering Design, Fourth edition, Elsevier Butterworth-Heinemann, 2005, p331, Vol 6, appendix C.

[25] G. Towler and R. Sinnott ,Chemical Engineering Design Principles, Practice and Economics of Plant and Process Design, USA: Butterworth-Heinemann is an imprint of Elsevier, 2008.

[26] C. Jotinkhisty, J. Mohammadi, A. A. Amekudzi, Systems Engineering With Economics, Probability, And Statistics, Second Edition, USA: J. Ross Publishing, 2012.

[27] A.E. Kabeel ,Emad M.S. El-Said, Applicability of flashing desalination technique for small scale needs using a novel integrated system coupled with nanofluid-based solar collector, Desalination 333, pp.10-22, 2014.

[28] Saudi electricity company official web site.[Online].Available:https://www.se.com.sa/en-us/Customers/Pages/TariffRates.asp.

\section{AUTHOR PROFILE}

Faissal Abdel-Hady is an Associate Professor in Chemical and Materials Engineering Department of King Abdulaziz University. He completed his PhD from Ain Shams University in Egypt in 1988. He is a Consultant for the Vice President of Graduate Studies and Scientific Research; in matter of improving research strategies of King Abdul Aziz University, Jeddah, Saudi Arabia. The interested research fields are the polymer nanofiber science and technology, modelling, simulation and analysis using finite element approach, advanced materials for new and renewable energy, polymer synthesis and processing, manufacturing of composite materials, new and renewable energy, advanced automatic control and fuzzy logic for industrial control systems 
Mahmoud El-Halwagi is a Professor, Holder of the McFerrin Professorship, Managing Director of TEES Gas and Fuels Research Center, Artie McFerrin Department of Chemical Engineering. He completed his PhD from University of California - Los Angeles, 1990. The interested research fields are the Process synthesis, simulation, design, operation, integration, optimization \& product design, Sustainable design of integrated biorefineries, oil and gas processes, and chemical process industries.

Mohammed Alghamdi is undergoing his $\mathrm{PhD}$ degree from Chemical and Materials Engineering Department of King Abdulaziz University. His thesis is based on Modelling, Analysis, and Optimization of energy utilization for solar driven humidification / dehumidification desalination process in which theabove project work is part of his thesis requirement.

AbdulrahimAlzahrani is a Professor in Chemical and Materials Engineering Department also served as Vice Dean of Graduate Research studies in King Abdulaziz University. He completed his PhD from Oregon State University, USA in 1988.

Abdel-Hamid Mazher is a Professor in Nuclear Engineering Department of King Abdulaziz University. He completed his PhD from Georgia Institute of Technology, USA in 1987 